\title{
Models for Forecasting the Demand and Supply of Electricity in Nigeria
}

\author{
Benjamin Oyediran Oyelami $^{1, *}$, Adedamola adedoyin Adewumi ${ }^{2}$ \\ ${ }^{1}$ Theoretical Physics, National Mathematical Centre, Abuja, Nigeria \\ ${ }^{2}$ Department of Mathematics, University of Abuja, Nigeria \\ *Corresponding author: boyelami2000@yahoo.com
}

Received December 16, 2013; Revised February 20, 2014; Accepted March 10, 2014

\begin{abstract}
In this paper, the Garch model is used to determine the market volatility in the demand and supply chains of electricity in Nigeria for 36 years, i.e. from 1970 to 2005 from the historic data obtained from the National Bureau of Statistics. The Harvey logistic model is used to predict the demand and supply of electricity in the country from 2005 to 2026. From the results obtained, the demand and supply of electricity show mixture of spikes because of mean reverse behavior about the mean values and the demand outweighed the supply. The consequence of this is that there is vast market prosperity for investors in the power sector in Nigeria. It is estimated that about 317.5 billion US dollars business opportunities are available to new independent power stations in Nigeria.
\end{abstract}

Keywords: demand, supply, electricity, garch, Arima, Harvey logistic model

Cite This Article: Benjamin Oyediran Oyelami, and Adedamola adedoyin Adewumi, "Models for Forecasting the Demand and Supply of Electricity in Nigeria.” American Journal of Modeling and Optimization, vol. 2, no. 1 (2014): 25-33. doi: 10.12691/ajmo-2-1-4.

\section{Introduction}

Electricity power supply is the most important commodity for the development of a nation. People become easily empowered to work and develop themselves when there is electricity power supply. This development takes place from domestic level to industrial level and can also be transferred from small to medium and to large scale level. Power consumption demand depends on the population and industrialization of a country $[2,4,5,15]$. There is power equilibrium when the supply is equal to the demand, otherwise there is supply shortfall.

Models for pricing, forecasting and supply of electricity are often characterized by spikes. Electricity is nonstorable, hence the market is volatility and will change with time, and that is, the volatility has heteroscedasicity behavior which is a kind of time varying variance [13,14]. There are several researches done on modeling and forecasting the demand and supply of electricity. Oyelami [14] studied the dynamics of demand and supply of electricity pricing and Barlow's model was used to suggest that capping happen at some maximum price whenever demand exceeds the maximum supply.

Electricity supply in Nigeria dates back to 1886 when two small generating sets were installed to serve the then colony of Lagos. By an act of parliament in 1951, the Electricity Corporation of Nigeria (ECN) was established and in 1962, the Niger Dams Authority (NDA) was also established. However, a merger of the two was made in 1972 to form the National Electric Power Authority
(NEPA) as a result of unbundling and power reform process, it was renamed Power Holding Company of Nigeria (PHCN) in 2005 [15]. In February 2005, the World Bank agreed to provide PHCN with $\$ 100$ million to assist in its privatization efforts. In November 2013, the Federal government of Nigeria (FGN) concluded the privatization of power sector in Nigeria which led to selling of the PHCN to some privately owned companies.

Nigeria is a country blessed with a lot of resources such as coal, oil, natural gas, water and other renewable energy sources that can be used to generate electricity. The renewable energy being solar energy, biomass, wind, small and large hydropower with potential for hydrogen fuel, geothermal and ocean energies. Nigeria is Africa's major oil producing country which accounts for two-thirds of Africa's crude oil reserves. Talking about Nigerian natural gas reserves, it is estimated to be 187.44 trillion standard cubic feet in 2005 [16]. These reserves are known to be substantially larger than its oil reserves in terms of energy. Gas utilization for generation of electricity is said to be a primary goal for Nigeria. The first discovery of coal was in the year 1909; the mining began in 1916 with a recorded output of about 24,500 tons [5]. The poor industrialization and varying economic growth in Nigeria may be attributed to unreliable and inadequate power supply.

The socio-economic development activities in the country are responsible for the increase in demand for electricity. Mostly, this high demand can be found in the manufacturing and commercial sub-sectors. The problem of Nigeria appears to be lower electricity supply compared to the electricity consumption. 
As at 2007, Nigeria has about 14 generating plants with an installed capacity of $7,876 \mathrm{MW}$ but the installed available capacity is less than 4000MW as at 2009. Nigerian electricity supply market has a lot of potential profit to investors if they invest in the generation, transmission and distribution of electricity. Generation of electric power in Nigeria is overwhelmed by excessive demand for electricity by consumers because of inadequate supply. This supply shortfall has resulted into unannounced load shedding, prolonged and intermittent power outages supplies to the consumers over the years. The total amount of electricity generated in Nigeria as at August 2013 dropped to 2,628.6 Megawatts [15].

Traditional financial models start with the BlackScholes assumption of the Geometric Brownian Motion or log-normal prices. This assumption does not make sense in the context of electricity prices for many reasons including the non-predictability of electricity prices. A model which has been used in practice is known as the Ornstein-Uhlenbeck process. This is a continuous time model which permits autocorrelation. It is necessary to incorporate mean reversion when modeling electricity prices because of the electricity price jumps due to unexpected events.

Basically, there are three stages involved in the business of electricity; these stages are the generation, transmission and distribution of electricity. Power generation, transmission and distribution involve flow of currents with heat losses in conductors. These losses can be reduced through better design, construction and maintenance.

Objective of this paper is to compute the volatility of the electricity market by using the General Autoregressive Conditional Heteroscedasicity (GARCH) model and then predict the demand and supply of electricity in the country $[7,8,12]$. The Nigerian electricity market has been our focus. The data to be used is the yearly generation and consumption of electricity in Nigeria as obtained from the National Bureau of Statistics. The data spans from 1970 to 2005. From the available data on demand and supply of electricity there appear to be different kind of shortfall scenarios in the demand and supply chains in the country as far as electricity is concerned.

\section{Methods}

We shall use the GARCH models to study for changing volatility in demand and supply chain for period of 36 years, i.e. from 1970 to 2005. We will then make use of the Harvey logistic model to predict the demand and supply of electricity for country from 2015 to 2026.

\subsection{Autoregressive Moving Average (ARMA) and Autoregressive Integrated Moving Average (ARIMA)}

This class of stochastic process denoted by $\operatorname{ARMA}(p, q)$ is a combination of autoregressive process of order $p$ and a moving average of order q parameterized as

$$
r_{t}=\phi_{1} r_{t-1}+\ldots+\phi_{p} r_{t-p}+\varepsilon_{t}-\beta_{1} \varepsilon_{t-1}-\ldots-\beta_{q} \varepsilon_{t-q}
$$

Or equivalently in a compact form we have $\phi(L) r_{t}=\beta(L) \varepsilon_{t}$

Where

$$
\begin{aligned}
& \phi(L)=1-\phi_{1} L-\phi_{2} L^{2}-\ldots-\phi_{p} L^{p} \\
& \beta(L)=1-\beta_{1} L-\beta_{2} L^{2}+\ldots+\beta_{q} L^{q}
\end{aligned}
$$

If $\mathrm{p}$ and $\mathrm{q}$ are integers and $d \in(0,1)$ we say that the time series $r_{t}$ is an ARIMA (p, d, q) series if $(1-d)^{d} r_{t}$ is stationary. ARMA (p, q) time series is defined by the infinite sum

$$
(1-L)^{d}=1+\sum_{j=0}^{\infty} \frac{d(d-1) \ldots(d-j+1)}{j !}(-1)^{d-j} L^{j}
$$

Where the difference operator $(1-d)^{d}$

If after the $d$ differencing, we can represent the above equation as

$$
\begin{aligned}
& \phi(L) \nabla^{d} r_{t}=\beta(L) \varepsilon_{t} \\
& \phi(L)(1-L)^{d} r_{t}=\beta(L) \varepsilon_{t}
\end{aligned}
$$

Thus we have an ARIMA (p, d, q) model corresponding to an invertible ARMA (p, q) model after the $d^{\text {th }}$ differencing. An examination of ARIMA (p, d, q) model shows that it varies generally with different combinations of $\mathrm{p}$ and $\mathrm{q}$. We can possibly generate a wide range of time series models, if $d=0$, the ARIMA model reduces to an ARMA model and when $p=d=q=0$, it becomes a pure white noise.

\subsection{Volatility}

Statistically, we can say it is the measure of dispersion of returns for a given security or market index. Volatility can either be measured by using the standard deviation or variance between returns from the same security or market index. Commonly, the higher the volatility, the riskier the security. As regards option pricing, it is described as a variable expressing the extent to which the return of the underlying asset will fluctuate between now and the expiration date. In other words, volatility refers to the amount of uncertainty of risk about the size changes in the value of an asset. The mathematical representation of volatility is given as $\sigma=\sqrt{\frac{1}{(n-1)} \sum(X-\bar{X})^{2}}, \quad \sigma$ represents the volatility, $n$ represents the number of observed elements, $X$ represents each observed element and $\bar{X}$ represents the mean of all observed elements.

\subsection{Data and Descriptive Statistic}

The data employed in this study contains the demand and supply of electricity commodity in Nigeria. The figures span from 1970 to 2005 amounting to 36 data points. The choice of this dataset was limited to the availability of data especially the absence of monthly figures for demand and supply of electricity which is expected to give us high frequency. All the annual data 
series were obtained from the National Bureau of Statistics, Abuja, Nigeria.

Basically, it is a known fact that in nature, most economic series are non-stationary. We can therefore perform different types of transformation on the data series in order for us to make it stationary.

Let $P_{t}$ denote value at time $\mathrm{t}$ and $P_{t-1}$ the value at time $\mathrm{t}-1$, and then the continuous compounded returns $r_{t}$ are calculated from the corresponding first difference of the log of values expressed in percentage as

$$
r_{t}=\ln \left[\frac{P_{t}}{P_{t-1}}\right] * 100
$$

Our choice of the compounded returns above is due to the fact that we wish to linearize the trend which definitely leads to a stable variance. The compounded returns also exhibit additive property which is not shared by relative returns. This better illustrates this property; we wish to use the theorem given below:

THEOREM 1 [6]

$$
\text { If } X_{t}=\varsigma_{t} \delta_{t} \text {, where } \delta_{t}=\left(\sum_{i=1}^{p} x_{i}(t) \cdot c_{i}\right)
$$

Then

$$
\nabla \log x_{t}=\nabla \varsigma_{t}+\nabla \delta_{t}
$$

is a stationary process.

\section{Proof}

The only term we considered is $\nabla \eta_{t}$. Differencing the function

$$
\begin{gathered}
\log \left(\sum_{i=1}^{p} x_{t}(t) \cdot c_{i}\right) \text { This leads to the results: } \\
\nabla \log \left(\sum_{i=1}^{p} x_{t}(t) \cdot c_{i}\right)=\sum_{i=1}^{p} \log \left(x_{t}(t) \cdot c_{i}\right) \\
\nabla \log x_{i}(t) \cdot c_{i}=\left\{\begin{array}{cc}
0 & \text { if } t \neq a_{i} \\
c_{i} & \text { if } t=a_{i-1} \\
-c_{i} & \text { if } t=a_{i}
\end{array}\right.
\end{gathered}
$$

Hence we have a zero difference except at the partition point where the result is $\nabla \log \delta_{t}=c_{i}-c_{i-1}$ if $t=a_{i}, \quad 0<i<p$. This completes the proof.

\subsection{Tests for Stationarity}

We wish to carry out checks on the respective return series which we obtained in order to find out if they are stationary or not. As stated above, this procedure is very much necessary due to the fact that no inference procedure can be applied to non-stationary series. Non-stationary series do not produce reliable estimates of parameters. We examined the graphs of both the demand-supply series and their return series with their respective Auto Correlation Form(ACF) and Partial Auto Correlation Form(PACF) to form a reasonable opinion on whether the series are stationary or not $[6,14]$.

\subsection{Estimation of the GARCH $(1,1)$ Model}

The descriptive statistics and other properties of return series such as mean, variance, mean, median, kurtosis, skewness, standard deviation etc. have serious implications for modeling. This is due to the fact that they provide good decision for the distribution and process that drives it.

We shall estimate the parameters $\alpha_{0}, \alpha_{1}$, and $\alpha_{2}$ of the GARCH $(1,1)$ model using the Matlab. From the estimation we wish to obtain the market volatility. The GARCH model is given as

$$
y_{t}=c+\varepsilon_{t}, \sigma_{t}^{2}=\alpha_{0}+\alpha_{1} \sigma_{t-1}^{2}+\alpha_{2} \varepsilon_{t-1}^{2}
$$

Where

$y_{t}$ Represents the returns

$\varepsilon_{t}$ Represents the error term (white noise)

$\sigma_{t}^{2}$ Represents the variance at time $\mathrm{t}$

$\sigma_{t-1}^{2}$ Represents the variance at a previous time $\mathrm{t}-1$

$\varepsilon_{t-1}^{2}$ Represents the error term at a previous time t-1

\subsection{Derivation of the Electricity Demand and Supply Functions Using the Harvey Logistic Model}

We are interested in developing a function for the demand of electricity commodity. Therefore we wish to use the Harvey Logistic Model $[9,11]$ given below;

$$
\ln y_{t}=2 \ln y_{t-1}+\eta t+\varepsilon_{i}
$$

Where $Y_{t}$ is the electricity consumption in year $\mathrm{t}$ and $y_{t}=Y_{t}-Y_{t-1}$ for $\mathrm{t}=2 \ldots \mathrm{T}$.

$\varepsilon_{t}$ is a disturbance term with zero mean and constant variance.

We shall therefore use ordinary least square method of regression to calibration the model.

Therefore, $\quad \ln y_{t}=2 \ln y_{t-1}+\eta t+\varepsilon_{i} \quad$. Now let $\ln y_{t}=w_{t}$ and $u_{t}=\ln y_{t-1}$

Hence,

$$
\begin{gathered}
w_{t}=2 u_{t}+\eta t+\varepsilon_{i} \\
\sum_{t=1}^{n} w_{t}=2 \sum_{t=1}^{n} u_{t}+\eta \sum_{t=1}^{n} t+\varepsilon_{i} n \\
=2 \sum_{t=1}^{n} u_{t}+\eta \frac{n}{2}(n+1)+\varepsilon_{i} n
\end{gathered}
$$

If we multiply equation (5) by $u_{t}$, then we have

$$
\begin{gathered}
u_{t} w_{t}=2 u_{t}^{2}+\eta \frac{n}{2}(n+1) t u_{t}+\varepsilon_{t} u_{t} \\
\sum_{t=1}^{n} u_{t} w_{t}=2 \sum_{t=1}^{n} u_{t}^{2}+\eta \frac{n}{2}(n+1) t \sum_{t=1}^{n} u_{t}+\varepsilon_{t} \sum_{t=1}^{n} u_{t}
\end{gathered}
$$

We will use the ordinary least square method of regression [3] to obtain the disturbance or error term $\varepsilon_{t}$ and $\eta$.

The supply function formula can be obtaining from the equation below: 


$$
\begin{aligned}
& \sum p_{t}=2 \sum_{t=1}^{n} u_{t}+\eta \frac{n}{2}(n+1)+\varepsilon_{i} n \\
& \sum_{t=1}^{n} p_{t} q_{t}=2 \sum_{t=1}^{n} q_{t}^{2}+\eta \frac{n}{2}(n+1) t \sum_{t=1}^{n} q_{t}+\varepsilon_{t} \sum_{t=1}^{n} q_{t}
\end{aligned}
$$

\section{Results}

The data analyzed in this study consist of both the demand and supply available data for electricity for the Nigerian electricity market. Each data is represented by a series of 36 data points, so there are two different series with a total of 72 data points. Their time plots are presented in Figure 1. All computations and analysis are done using the matrix laboratory (MATLAB) software package and the statistical package for social sciences (SPSS).

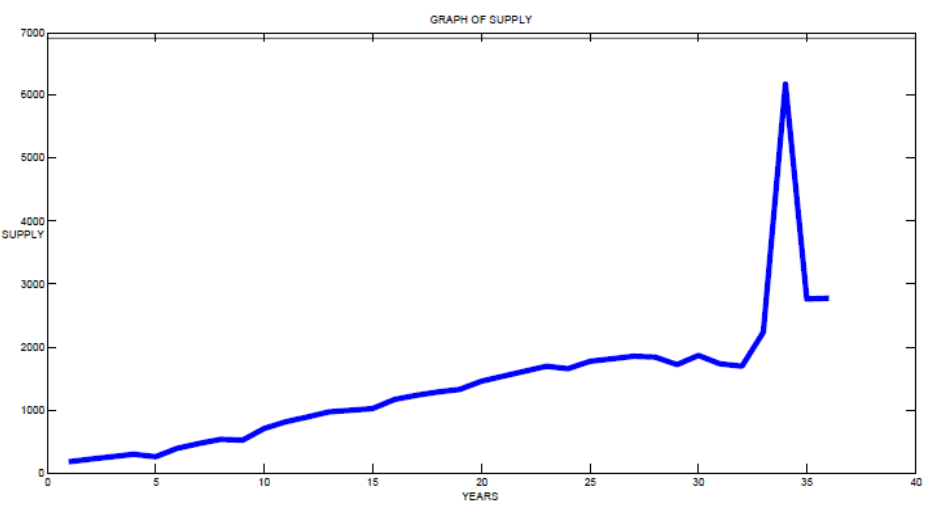

Figure 1. Time plot of the yearly supply of electricity. Source: Nigerian Bureau of Statistics

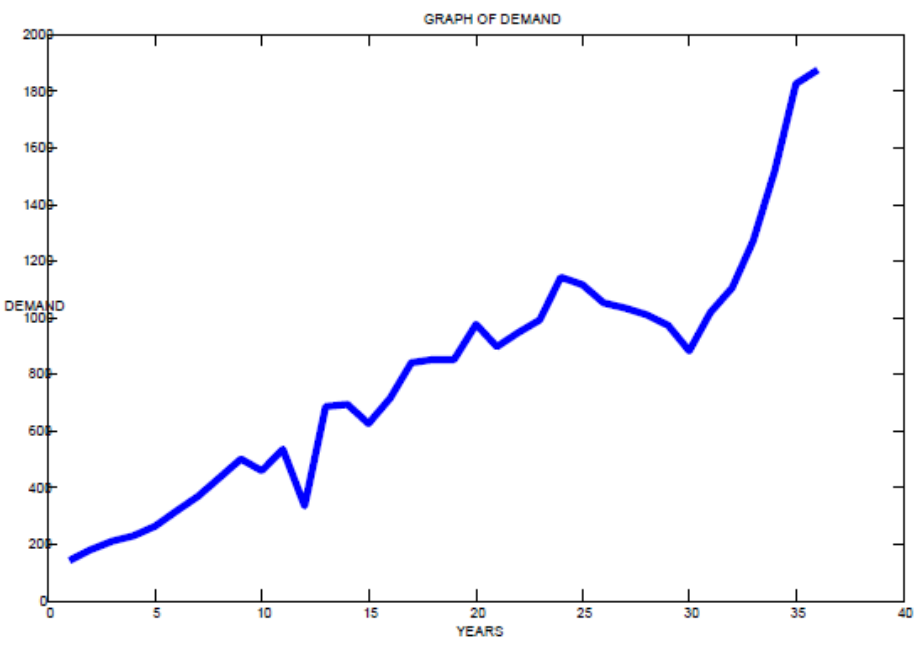

Figure 2. Time plot of the yearly demand of electricity, Source: Nigerian Bureau of Statistics

\subsection{Continuous Compounded Returns}

We transformed the supply and demand series into returns series in order to eliminate the effects of the random variations detected in the plots of the supply and demand data series. The results obtained by the use of equation (1) are presented below:

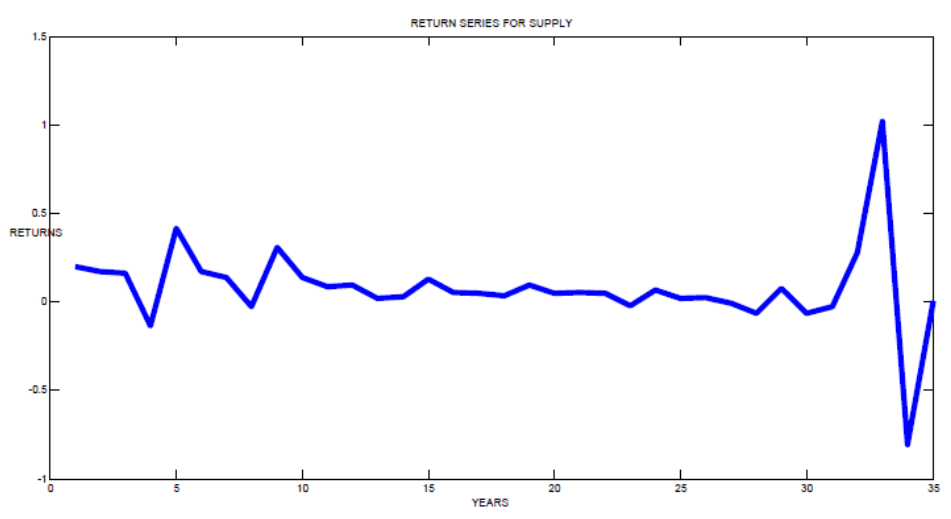

Figure 3. Time plot of supply returns 


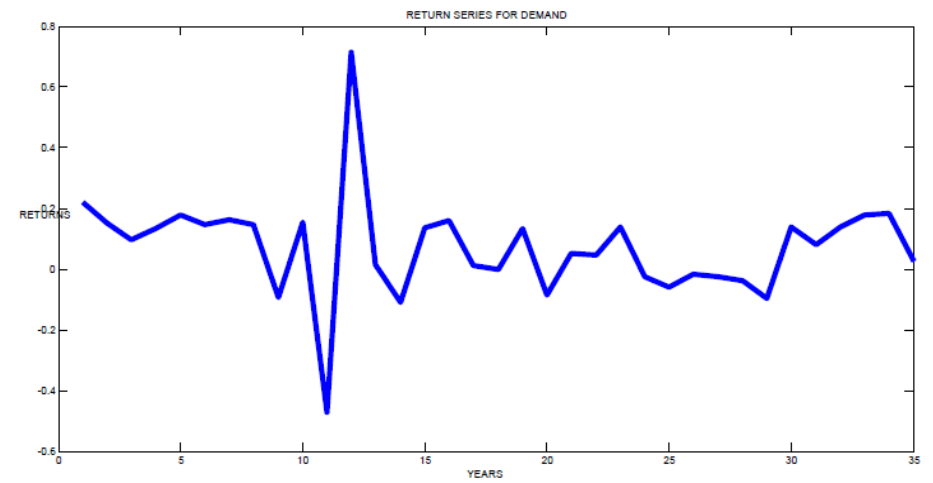

Figure 4. Time plot of demand returns

In the demand and supply return time plots in Figure 1 and Figure 2 there is stationarity in the return series. The demand shows mean reversal property. It goes up and returns to the mean and goes down and returns to the mean. There are also spikes in the demand and supply because of data size which is small because of the information in the Table 1 and Table 2 were on annual basis which led to smaller spikes.

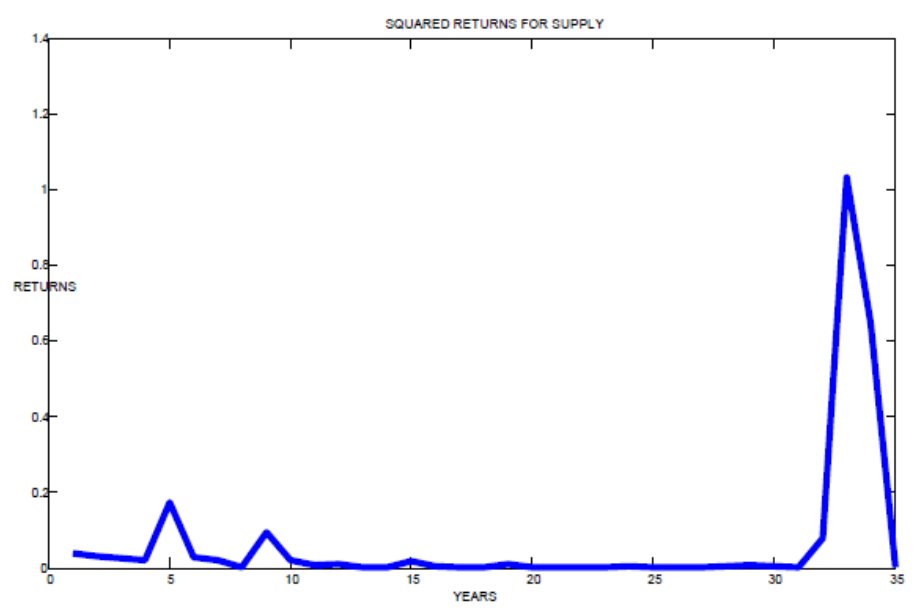

Figure 5. Time plot of supply squared returns

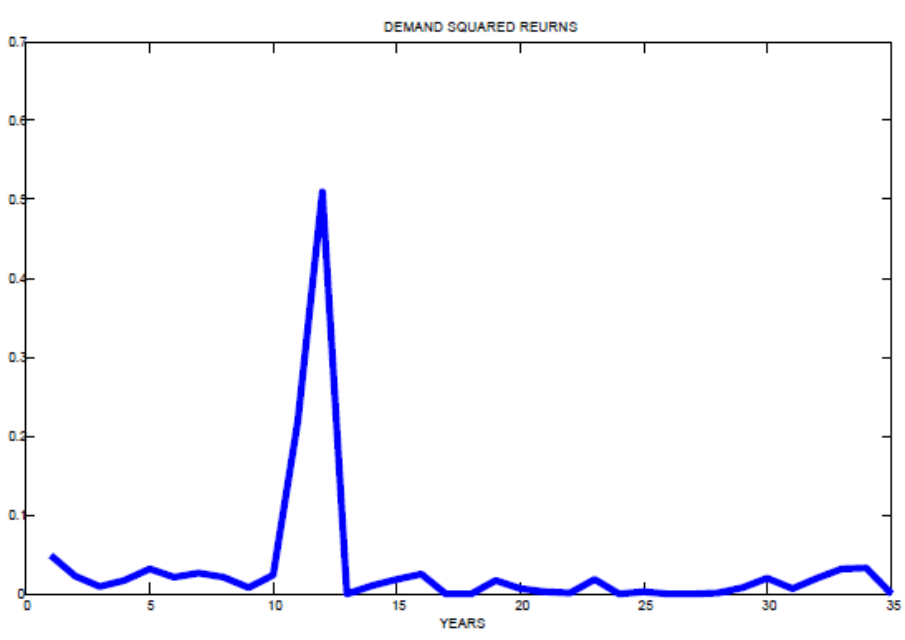

Figure 6. Time plot of demand squared returns

The noticeable feature of the two time series of returns suggests that fluctuations occurred at different amplitudes though very low amplitudes. There are periods of very short turbulence and longer period of relative calmness. This is due to the fact that our data series is very small. However, square return allows perfect stationarity. The Figure 5 is the time plot of supply squared returns and Figure 5 is the time plot of demand squared returns to allow the data to be stationary.

Table 2 provides the general overview and preliminary statistics of the respective returns for both data series obtained for the period under preview. These include the mean, minimum, maximum, standard deviation skewness and kurtosis. The large difference between the maximum and minimum is due to the fact that there are some levels of fluctuations in the returns. The mean and standard deviation of the two data series are significant. Both series are leptokurtic in nature although there is no indication of negative skewness due to the size of the data.

Using the SPSS software we obtained the following results: 
Table 1. Descriptive statistics for the return series

\begin{tabular}{|c|c|c|c|c|c|c|c|}
\hline & SAMPLE SIZE & MEAN & MIN & MAX & STD DEV & SKEW & KURT \\
\hline SUPPLY & 36 & 0.0809 & -0.8048 & 1.0160 & 0.2499 & 0.333 & 9.763 \\
\hline DEMAND & 36 & 0.7310 & -0.4690 & 0.7135 & 0.1725 & 0.542 & 7.015 \\
\hline
\end{tabular}

Skew is a measure of heavy tails and asymmetry of a distribution (normal) and kurtosis is measure of too many observations around the mean for a distribution (normal).

The Matlab code for estimating the garch parameters is:

$>$ whos

$>>$ y=price2ret (demand);

$>>$ [coeff, errors, LLF, innovations, sigma, summary] $=$ garchfit $(\mathrm{y})$;

>> garchdisp (coeff, errors);

From the garch parameter code we obtained the results in the Table 2 and the Table 3 as follows:

Table 2.Parameter estimation of GARCH (1,1) for the supply data
series
\begin{tabular}{|c|c|c|c|}
\hline PARAMETER & VALUE & T-ERROR & STATISTICS \\
\hline $\mathrm{C}$ & 0.054263 & 0.0075726 & 7.1657 \\
\hline $\mathrm{a}_{0}$ & 0.0029131 & 0.0025178 & 1.11570 \\
\hline $\mathrm{GARCH}(1)$ & 0 & 0.17768 & 0.0000 \\
\hline $\mathrm{ARCH}(1)$ & 1 & 0.13258 & 7.5427 \\
\hline
\end{tabular}

Table 3. Parameter estimation of GARCH $(1,1)$ for the Demand data series

\begin{tabular}{|c|c|c|c|}
\hline PARAMETER & VALUE & T-ERROR & STATISTICS \\
\hline $\mathrm{C}$ & 0.029746 & 0.0023232 & 1.2804 \\
\hline $\mathrm{a}_{0}$ & 0.0057212 & 0.010356 & 0.5525 \\
\hline GARCH(1) & 0.022733 & 0.46612 & 0.0488 \\
\hline ARCH(1) & 0.97727 & 0.77949 & 1.2537 \\
\hline
\end{tabular}

From Table 1, we can therefore set up the GARCH $(1,1)$

$$
\begin{aligned}
& y_{t}=0.054263+\varepsilon_{t} \\
& \sigma_{t}^{2}=0.0057212+\varepsilon_{t}^{2}
\end{aligned}
$$

From Table 3, we can therefore set up the GARCH (1, 1) model with the appropriate estimated values as follows:

$$
\begin{aligned}
& y_{t}=0.029746+\varepsilon_{t} \\
& \sigma_{t}^{2}=0.0057212+0.022733 \sigma_{t-1}^{2}+0.97727 \varepsilon_{t-1}^{2}
\end{aligned}
$$
model with the appropriate estimated values:

From the above equation, we used the Monte Carlo simulation to obtain the white noise $\varepsilon_{t}$ from the demand data series, from which we now obtained the variance to be 0.0066 .

Hence our volatility $=\sqrt{0.0066}=0.0812 * 100=8.12 \%$.

\begin{tabular}{|c|c|c|c|c|c|c|}
\hline supply & $Z_{t}=Z_{t}-Z_{t-1}$ & $\ln z_{t}$ & $Z_{t}=p_{t}$ & $z_{t-1}=p_{t}$ & $p_{t} q_{t}$ & $q_{t}^{2}$ \\
\hline 176.6 & 176.6 & 5.1739 & 5.1739 & & & \\
\hline 215.4 & 38.8 & 3.6584 & & 3.6584 & 18.7215 & 13.3839 \\
\hline 255.4 & 40.0 & 3.6889 & 3.6889 & & & \\
\hline 299.7 & 44.3 & 3.7910 & & 3.7910 & 13.9846 & 14.3717 \\
\hline 261.1 & -38.6 & 3.6533 & 3.6533 & & & \\
\hline 395.4 & 134.3 & 4.8978 & & 4.8978 & 17.8931 & 23.9884 \\
\hline 468.7 & 73.3 & 4.2946 & 4.2946 & & & \\
\hline 538.0 & 69.3 & 4.2384 & & 4.2384 & 18.2022 & 17.9640 \\
\hline 522.7 & 15.3 & 2.7279 & 2.7279 & & & \\
\hline 710.7 & 188 & 5.2364 & & 5.2364 & 14.2844 & 27.4199 \\
\hline 815.1 & 104.4 & 4.6482 & 4.6482 & & & \\
\hline 887.7 & 72.6 & 4.2850 & & 4.2850 & 19.9175 & 18.3612 \\
\hline 973.9 & 86.2 & 4.4567 & 4.4567 & & & \\
\hline 994.6 & 20.7 & 3.0301 & & 3.0301 & 13.5042 & 9.1815 \\
\hline 1025.5 & 30.9 & 3.4308 & 3.4308 & & & \\
\hline 1166.8 & 141.3 & 4.9509 & & 4.9509 & 16.9855 & 24.5114 \\
\hline 1228.9 & 62.1 & 4.1287 & 4.1287 & & & \\
\hline 1286.0 & 57.1 & 4.0448 & & 4.0448 & 16.6998 & 16.3604 \\
\hline 1330.4 & 44.4 & 3.7932 & 3.7932 & & & \\
\hline 1462.7 & 132.3 & 4.8801 & & 4.8801 & 18.5112 & 23.8154 \\
\hline 1536.9 & 74.2 & 4.3068 & 4.3068 & & & \\
\hline 1617.2 & 80.3 & 4.3858 & & 4.3858 & 18.8888 & 19.2352 \\
\hline 1693.4 & 76.2 & 4.3334 & 4.3334 & & & \\
\hline 1655.8 & -37.6 & 3.6270 & & 3.6270 & 15.7172 & 13.1551 \\
\hline 1772.9 & 117.1 & 4.7630 & 4.7630 & & & \\
\hline 1810.1 & 37.2 & 3.6163 & & 3.6163 & 17.2244 & 13.0776 \\
\hline 1854.2 & 44.1 & 3.7865 & 3.7865 & & & \\
\hline 1839.8 & -14.4 & 2.6672 & & 2.6672 & 10.0991 & 7.1140 \\
\hline 1724.9 & -114.9 & 4.7441 & 4.7441 & & & \\
\hline 1859.8 & 134.9 & 4.9045 & & 4.9045 & 23.2674 & 24.0541 \\
\hline 1738.3 & -121.5 & 4.7999 & 4.7999 & & & \\
\hline 1689.9 & -48.4 & 3.8795 & & 3.8795 & 18.6212 & 15.0501 \\
\hline 2237.3 & 547.4 & 6.3052 & 6.3052 & & & \\
\hline 6180.0 & 3942.7 & 8.2796 & & 8.2796 & 52.2045 & 68.5518 \\
\hline 2763.6 & -3416.4 & 8.1363 & 8.1363 & & & \\
\hline \multirow[t]{2}{*}{2779.3} & 15.7 & 2.7537 & & 2.7537 & 22.4050 & 7.5829 \\
\hline & & & 81.1714 & 77.1265 & 347.1315 & 357.1786 \\
\hline
\end{tabular}

\subsection{Statistical Computation on Demand and Supply Variables}

Table 4. Statistical computation on Electricity supply 
Table 5. Statistical table for Electricity Demand

\begin{tabular}{|c|c|c|c|c|c|c|}
\hline consumption & $y_{t}=Y_{t}-Y_{t-1}$ & $\ln y_{t}$ & $y_{t}=w_{t}$ & $y_{t-1}=u_{t}$ & $w_{t} u_{t}$ & $u_{t}^{2}$ \\
\hline 145.3 & 145.3 & 4.9788 & 4.9788 & & & \\
\hline 181.1 & 35.8 & 3.5779 & & 3.5779 & 17.8136 & 12.8014 \\
\hline 211.1 & 30.0 & 3.4012 & 3.4012 & & & \\
\hline 232.7 & 21.6 & 3.0727 & & 3.0727 & 10.4509 & 9.4415 \\
\hline 266.2 & 33.5 & 3.5115 & 3.5115 & & & \\
\hline 318.7 & 52.5 & 3.9608 & & 3.9608 & 13.3121 & 15.6879 \\
\hline 369.8 & 51.1 & 3.9338 & 3.9338 & & & \\
\hline 435.7 & 65.9 & 4.1881 & & 4.1881 & 16.4751 & 17.5402 \\
\hline 504.4 & 68.7 & 4.2297 & 4.2297 & & & \\
\hline 460.1 & -44.3 & 3.7910 & & 3.7910 & 16.0348 & 14.3717 \\
\hline 536.9 & 76.8 & 4.3412 & 4.3412 & & & \\
\hline 335.9 & -210 & 5.3033 & & 5.3033 & 23.0227 & 28.1250 \\
\hline 685.6 & 349.7 & 5.8571 & 5.8571 & & & \\
\hline 696.7 & 11.1 & 2.4069 & & 2.4069 & 14.0975 & 5.7932 \\
\hline 625.5 & -71.2 & 4.2655 & 4.2655 & & & \\
\hline 717.4 & 91.9 & 4.5267 & & 4.5267 & 19.2830 & 20.4367 \\
\hline 841.8 & 124.4 & 4.8235 & 4.8235 & & & \\
\hline 852.9 & 11.1 & 2.4069 & & 2.4069 & 11.6097 & 5.7932 \\
\hline 853.5 & 0.6 & -0.5108 & -0.5108 & & & \\
\hline 976.8 & 123.3 & 4.8146 & & 4.8146 & -2.4593 & 23.1804 \\
\hline 898.5 & -78.3 & 4.33605 & 4.33605 & & & \\
\hline 946.6 & 48.1 & 3.8733 & & 3.8733 & 16.8895 & 15.0025 \\
\hline 993.0 & 46.4 & 3.8373 & 3.8373 & & & \\
\hline 1141.4 & 148.4 & 4.9999 & & 4.9999 & 19.1861 & 24.9990 \\
\hline 1115.0 & -26.4 & 3.2734 & 3.2734 & & & \\
\hline 1050.9 & -64.1 & 4.1604 & & 4.1604 & 13.6187 & 17.3089 \\
\hline 1033.3 & -17.6 & 2.8679 & 2.8679 & & & \\
\hline 1009.6 & -23.7 & 3.1655 & & 3.1655 & 9.0783 & 10.0204 \\
\hline 972.8 & -36.8 & 3.6055 & 3.6055 & & & \\
\hline 883.7 & -89.1 & 4.4898 & & 4.4898 & 16.1880 & 20.1583 \\
\hline 1017.3 & 133.6 & 4.8949 & 4.8949 & & & \\
\hline 1104.7 & 87.4 & 4.4705 & & 4.4705 & 21.8827 & 19.9854 \\
\hline 1271.6 & 166.9 & 5.1174 & 5.1174 & & & \\
\hline 1519.5 & 247.9 & 5.5130 & & 5.5130 & 28.2122 & 30.3932 \\
\hline 1825.8 & 306.3 & 5.7246 & 5.7246 & & & \\
\hline 1873.1 & 47.3 & 3.8565 & & 3.8565 & 22.0770 & 14.8726 \\
\hline
\end{tabular}

We obtained the following from the supply data series

$$
\begin{aligned}
& \sum p_{t}=81.1714, \sum q_{t}=77.1265 \\
& \sum p_{t} q_{t}=347.1316, \sum q_{t}^{2}=357.1786
\end{aligned}
$$

We obtained the equations below

$$
\begin{aligned}
& -73.0816=+666 \eta+36 \varepsilon \\
& -367.2256=51366.249 \eta+77.1265 \varepsilon
\end{aligned}
$$

In matrix form we have,

$$
\begin{aligned}
& \left(\begin{array}{cc}
51366.249 & 77.1265 \\
666 & 36
\end{array}\right)\left(\begin{array}{l}
\eta \\
\varepsilon
\end{array}\right)\left(\begin{array}{c}
-367.2256 \\
-73.0816
\end{array}\right) \\
& \eta=-0.0042 \\
& \varepsilon=-1.9520
\end{aligned}
$$

The values of $\eta$ and $\varepsilon$ for the demand and supply variables and plotting of graphs are obtained using the following Mat lab code in the appendix. Hence, the supply function is given as

$$
\ln z_{t}=2 \ln z_{t-1}-0.0042 t-1.9520
$$

We, therefore, obtained the following from the demand series.

$$
\begin{aligned}
& \sum w_{t}=72.5130, \sum u_{t}=72.5718 \\
& \sum w_{t} u_{t}=286.7726, \sum u_{t}^{2}=305.9115
\end{aligned}
$$

We have two equations

$$
\begin{aligned}
& 72.513=145.1436+666 \eta+36 \varepsilon \\
& 286.7726=611.823+48332.8188 \eta+72.5718 \varepsilon
\end{aligned}
$$

Hence, in matrix form we have

$$
\begin{aligned}
& \left(\begin{array}{cc}
666 & 36 \\
48332.8188 & 72.5718
\end{array}\right)\left(\begin{array}{l}
\eta \\
\varepsilon
\end{array}\right)\left(\begin{array}{c}
-72.6306 \\
-325.0504
\end{array}\right) \\
& \therefore \eta=-0.0038 \text { and } \varepsilon=-1.9472
\end{aligned}
$$

The demand model is then given as

$$
\ln y_{t}=2 \ln y_{t-1}-0.0038 t-1.9472
$$




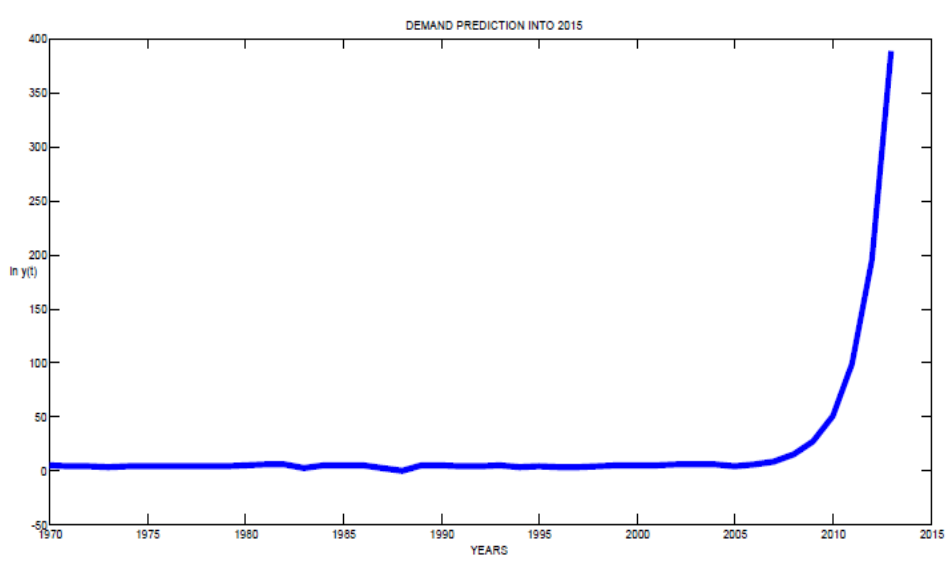

Figure 7. Graph of demand prediction

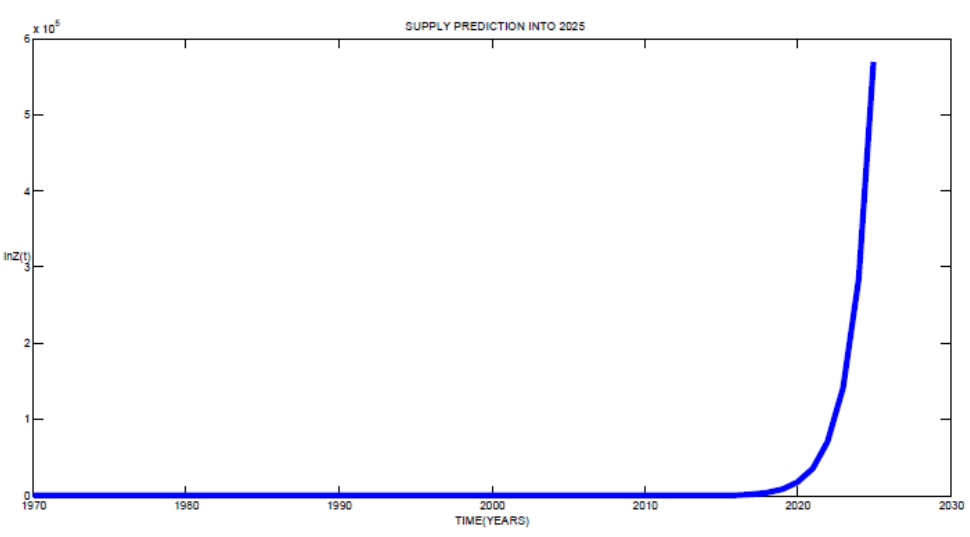

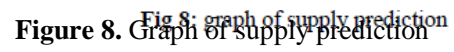

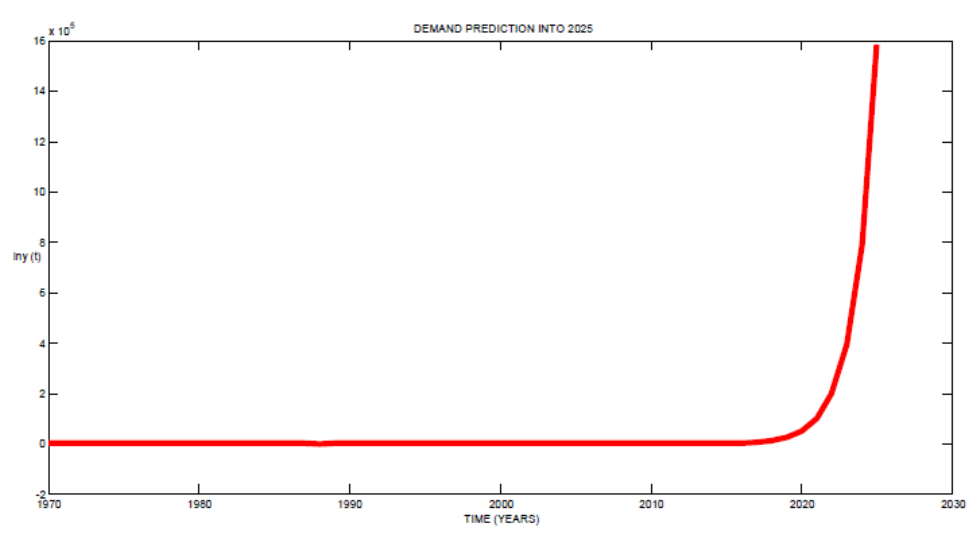

Figure 9. Demand of electricity prediction

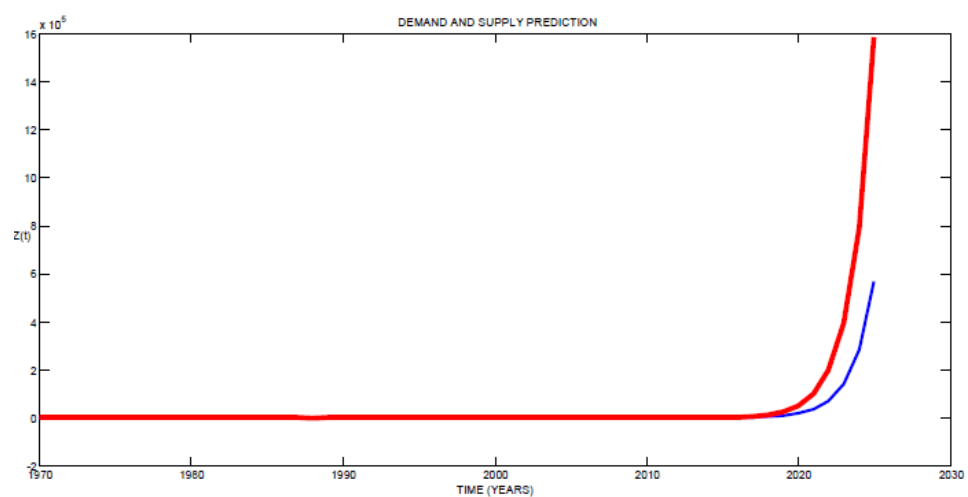

Figure 10. Graph of electricity demand and supply from 1970 to 2026 
The prediction for electricity demand and supply is obtained from the Harvey model by extrapolating the data from the year 2005 to 2026. The prediction value clearly indicts that the demand for electricity in Nigeria is continuously increasing and clearly outweighed the supply from Figure 10. Therefore, there are investment potentials for investors in the area of generation, transmission and distribution of electricity.

\section{Conclusion}

The National Electricity Regulation of Nigeria had suggested the minimum electricity requirement of Nigeria is about 50,000 Megawatts. At the moment the nation can boast of 4000 Megawatts, that is, a power shortfalls of about 46,000 Megawatts.1 kilowatt of electricity in Nigeria costs 13 naira and 165 naira is equivalent 1 US dollar. Therefore, the profit to be made if the shortfalls are supplied by new independent power stations, by simple calculation, is 317.48 billion US dollars. Therefore is vast window of opportunities open to investors in power section in Nigeria.

\section{Acknowledgements}

The authors are grateful to the National Mathematical Centre, Abuja and The University of Abuja, Nigeria. The authors are grateful to the National Mathematical Centre, Abuja and The University of Abuja, Nigeria. The authors appreciate the suggestion of the reviewers which help to improve the quality of the paper.

\section{References}

[1] Ackerman, G Short-Term Load Prediction for Electric-Utility Control of Generating Units. Comparative models for electrical Load forecasting, 1985, pp. 32-42, New York.

[2] Al-Alawi, S.M and Syed, M.Islam, Principles of Electricity Demand Forecasting: Part 1 Methodologies. Power Engineering Journal 10 (3), 1996, 139-143.

[3] Al-Garni, A.Z., Syed, M.Z. and Javeed, S.N. (1994) A Regression Model for Electric-Energy-consumption forecasting in Eastern Saudi Arabia. Energy, 19 (10), 1994. 1043-1049.

[4] Bilgin, M., Geopolitics of European Natural Gas Demand: Supplies from Russia, Caspian and Middle East. Energy Policy, 2009.

[5] Bamgbola M and Oke M Minimization of losses on electric power transmission line. Mathematical theory and modeling, Vol. 3, (7), 2013, 28-31.

[6] Bassey B E Modeling volatility of the Nigerian Stock return using time series models (heteroscedasicity approach). M.sc dissertation submitted University of Abuja, Nigeria, 2009.

[7] Bodger P.S and Tay, H.S 'Logistic and energy substitution Models for Electricity Forecasting: A Comparison Using New Zealand Consumption Data' Technological Forecasting and Social Change, Vol. 31, 1987, pp. 27-48.

[8] Dahl, C.A, A survey of Energy Demand Elasticities in Support of Development of the NEMS. US Department of Energy, 1993.
[9] Dilaver, Z and Hunt, L.C., Industrial Electricity for Turkey: A Structural Time Series Analysis. Energy Economics 33, 2011, pp. 426-436.

[10] Dapice, D. "Electricity demand and supply in Myanmar”. Electric Power Research Institute, (1977) "Forecasting and Modeling Time-of-Day and Seasonal Electricity Demands” EPRI EA-578SR, Palo Alto, CA. 2012.

[11] Harvey, Andrew and Siem Jan Koopmans, "Forecasting Hourly Electricity Demands Using Time-Varying Splines,” Journal of the American Statistical Association 88, 1993 pp 1228-1237.

[12] North America Electric Reliability Council "Electricity Supply and Demand for 1990-1999”. 1990,Princeton New jersey

[13] Jaimungal, S. IMPA Commodities course: Electricity Models, 2008.

http://www.utstat.utoronto.ca/sjaimung/courses/Commodities/Elec tricity.pdf

[14] Oyelami, B O "Models for pricing of electricity commodity". Mathematical Theory and modeling, Vol. 3 (1), 2013, 71-85.

[15] Sambo, A, Garba, B, Zarma, H and Gaji, M, Electricity Generation and the present Challenges in the Nigerian Power sector. Technical paper Energy Commission of Nigeria, AbujaNigeria, 2009.

[16] Solibakke, P.B., Describing the Nordic Forward electricity market: A stochastic model approach. International Journal of Business.11 (4), 2006, 345-349.

\section{Appendix}

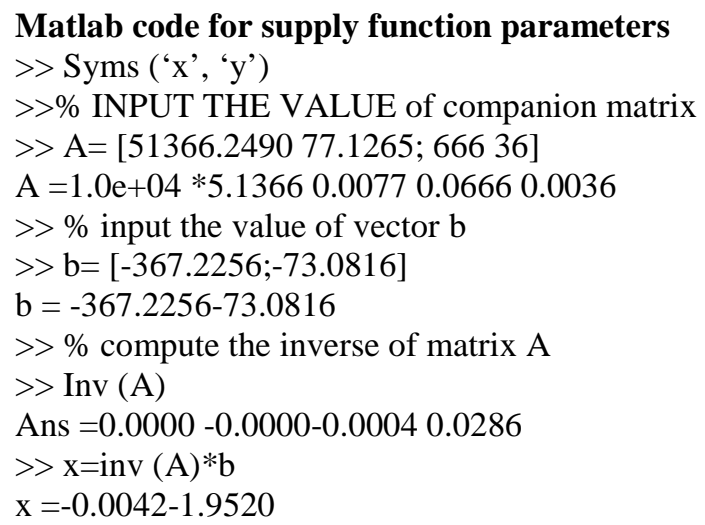

\section{Matlab code for demand function parameters}

$>>$ Syms (' $x$ ', 'y')

$>>\%$ Input the value of the companion matrix A2

$>>$ A2 $=$ [666 36; 48332.8188 72.5718]

A2 $=1.0 \mathrm{e}+04 * 0.06660 .00364 .83330 .0073$

$>>\%$ input the value of vector b2

$>>$ b2 $=$ [-72.6306;-325.0504]

b2 $=-72.6306-325.0504$

$>>\%$ compute the inverse of A2

$>>$ Inv (A2)

Ans $=-0.00000 .00000 .0286-0.0004$

$>>\mathrm{x}=\mathrm{inv}(\mathrm{A} 2) * \mathrm{~b} 2$

$\mathrm{x}=-0.0038-1.9472$

$>\mathrm{t}=1970: 1: 2013$

$>>\%$ import values of $\ln y$ and $\ln z$.

$>$ plot (t, lnz)

$>>$ plot (t, lny)

$>>$ plot (t, lnz, t, lny) 